\title{
Frequency of Low Birth Weight and its Relationship With Maternal Nutritional and Dietary Factors: A Cross-Sectional Study
}

\author{
Saira Jamshed ${ }^{1}$, Farah -. Khan ${ }^{1}$, Amna Begum ${ }^{2}$, Beena Barkat Ali ${ }^{3}$, Zuneera Akram ${ }^{4}$, Madiha Ariff ${ }^{5}$ \\ 1. Obstetrics and Gynecology, Hamdard University Hospital, Karachi, PAK 2. Obstetrics and Gynecology, Karachi \\ Medical and Dental College/Abbasi Shaheed Hospital, Karachi, PAK 3. Obstetrics and Gynecology, Agha Khan Hospital \\ for Women, Karachi, PAK 4. Pharmacology, Baqai Institute of Pharmaceutical Sciences, Baqai Medical University, \\ Karachi, PAK 5. Internal Medicine, Dow University of Health Sciences, Karachi, PAK
}

Corresponding author: Madiha Ariff, madiha.ariff@live.com

\begin{abstract}
Background: Low birth weight (LBW) is linked with fetal and neonatal mortality and morbidity; also it can slow down growth and cognitive development. Several factors contribute to pregnancy outcomes, including LBW deliveries, maternal nutrition, and additional dietary intake. Our study was aimed to identify the frequency and factors associated with LBW mothers in Karachi, Pakistan.

Methods: A cross-sectional survey was carried out at the Obstetrics and Gynaecological Department of Hamdard Hospital, Karachi. A total of 195 healthy pregnant females were enrolled. All the relevant data were collected from March 1st, 2019 to August 31st, 2019 with the help of a structured questionnaire designed specifically for the study where mothers were also asked about consumption of iron, vitamin, and extra meals since they became pregnant. Written, informed consent was taken from all of the participants before data collection. Data analysis was performed using a statistical package for the social sciences (SPSS) version 20.0. A Chi-square test was used for checking associations between the studied maternal factors and the weight of the children.
\end{abstract}

Results: There was a total of 195 pregnant females selected for the study. The frequency of LBW infants was found to be 57 (29.2\%) in these women. The mean age of the females was $29.29 \pm 5.22$ years, 142 (72.8\%) of them had a body mass index (BMI) of $25.0 \mathrm{~kg} / \mathrm{m}^{2}$ or more, $102(52.3 \%)$ of them had hemoglobin $(\mathrm{Hb})$ between 10 and $11 \mathrm{mg} / \mathrm{dL}$. The study results further showed that maternal $\mathrm{Hb}(\mathrm{p}=0.02)$, vitamin $\mathrm{C}$ intake $(\mathrm{p}=0.037)$, iron intake $(\mathrm{p}=0.01)$, and consumption of extra meals during pregnancy $(\mathrm{p}=0.021)$ were significantly associated with a LBW of the children. Mothers whose $\mathrm{Hb}<10 \mathrm{mg} / \mathrm{dL}$, no intake of vitamin C, or iron, and extra meals during pregnancy were more likely to have a child with LBW than others.

Conclusion: It can be concluded that maternal nutritional and dietary factors are very important during fetal development, and they have a significant relationship with the birth weight.

Received 06/03/2020

Review began 06/12/2020

Review ended 06/12/2020

Published 06/21/2020

() Copyright 2020

Jamshed et al. This is an open access article distributed under the terms of the Creative Commons Attribution License CC-BY 4.0., which permits unrestricted use, distribution, and reproduction in any medium, provided the original author and source are credited.
Categories: Family/General Practice, Obstetrics/Gynecology, Pediatrics

Keywords: low birth weight, mothers, diets, association, cross-sectional study

\section{Introduction}

According to the World Health Organization (WHO), low birth weight (LBW) is defined as the first weight after birth which is less than $2500 \mathrm{~g}$ (5.5 pounds), resulting from preterm birth (birth before 37 completed weeks) or due to intrauterine growth restriction or from both [1-2]. Birth weight not only predicts the health status of the mother but also gives future information about the survival, development, and long-term health of the baby. LBW is one of the important primary determinant and contributor to neonatal and infant mortality that contributes for nearly half of all perinatal and one-third of all infant deaths [3-4]. LBW babies have 40 times more chances to die within the first 30 days of life as compared to those with normal birth weight (NBW); so considering its importance, LBW has been used as an important health indicator of a public health problem as per directives of $\mathrm{WHO}$, because it reflects the malnutrition and metabolic conditions of the mother, as well as poor health care at population level during pregnancy, hence, it is the strongest predictor of newborn health and survival [1,5-7]. Developing countries of the world have been facing a very high burden of this condition with a $16.5 \%$ frequency of LBW, in comparison to developed countries (7\%). Specifically, a condition in South Asia is worse due to low socioeconomic status (SES), and poor health care during pregnancy; as the global estimate is 18 million babies born per year with LBW and 9.3 million (50\% of total) of them belong to South Asia [2]. However, Pakistan has made some progress in achieving Millennium Development Goals with a frequency of $12 \%-25 \%$, specifically in Lahore $21 \%$, and in Karachi $29 \%$ babies born with LBW by the year 2017 and 2018, respectively [8-10].

As we know, the nutritional needs during pregnancy are higher than usual days of life, and proper balance 
with extra nutrients can help both mother and fetus in protecting long-term health outcomes. Many physiological modifications in mother, as well as the growth of fetus, increase the metabolic demand, and inadequate maternal nutritional status showed adverse pregnancy outcomes, poor infant survival, and impaired intellectual development in the coming life [11-12]. Previous studies showed that the women who had consumed junk food, imbalanced diet, consumed less quantity of food, or those who escape meals during the first eight-week period of pregnancy are more prone to maternal mortality as well as fetal morbidity and mortality as compared to those who took healthily and enough quantity of meals. Hence, it is postulated that a well-fed mother gives birth to a healthy and normal weight child because they had a more favorable intrauterine environment [13]. There are many risk factors, for LBW including poor maternal nutrition and lifestyle factors such as the use of alcohol and tobacco; pregnancy complications such as hypertension, low socio-economic conditions, maternal age, maternal body composition, and parity $[1,14]$. Maternal health and nutritional status are modifiable risk factors that are particularly crucial in determining infant birth weight [1]. The intake of sufficient energy, protein, and nutrients to meet maternal and fetal requirements is required for optimal growth and birth weight, low nutritional diet, and inadequate weight gain during pregnancy contribute to fewer nutrients that are required for fetal growth, such as vitamins and iron. Iron promotes the formation of new hemoglobin $(\mathrm{Hb})$ and is responsible for an adequate supply of energy and oxygen to body organs [15-16]. Maternal anemia can develop when Hb levels drop below $11 \mathrm{~g} / \mathrm{dL}$, which may lead to the unavailability of iron in an extracellular environment for erythropoiesis [17]. This study was conducted to identify the frequency of LBW in the women of Karachi, Pakistan, and to explore the relationship of LBW with maternal nutritional and dietary factors among them.

\section{Materials And Methods}

A cross-sectional survey was carried out at the Obstetrics and Gynecological Department of Hamdard University Hospital, Karachi, among 195 healthy pregnant females. A nonprobability convenient sampling technique was used in this study. The ethical approval was taken from the institutional review board of the hospital. Taking the percentage frequency of the study outcome as $50 \%$ for the most liberal estimate, with a 95\% confidence level and $7.5 \%$ precision, the minimum calculated sample size was 171 pregnant females. Healthy pregnant females with either singleton or multiple pregnancies with at least three antenatal checkups were included while females giving birth at gestational age less than 34 weeks or above 41 weeks and 6 days, or with a complicated pregnancy were excluded from the study. Written, informed consent was taken from all of the participants before data collection. No incentive, monetary or otherwise, was offered to the study participants. All the relevant data were collected from March 1st, 2019 to August 31st, 2019 with the help of a structured questionnaire designed specifically for the study.

Data were analyzed using the Statistical Package for Social Sciences (SPSS) version 20.0. For descriptive analysis, means and standard deviations were calculated for continuous variables while frequencies and percentages were generated for categorical variables. Inferential analysis was performed using the chisquare test to check associations between the maternal factors and the weight of the children whereas the significance level was kept at 0.05 (p-value).

\section{Results}

There was a total of 195 pregnant females selected for the study. The frequency of LBW infants was found to be $57(29.2 \%)$ in these women. The mean age of the females was $29.29 \pm 5.22$ years, $142(72.8 \%)$ of them had a body mass index (BMI) of $25.0 \mathrm{~kg} / \mathrm{m} 2$ or more, 102(52.3\%) of them had Hb between 10 and $11 \mathrm{mg} / \mathrm{dL}$, $172(88.2 \%)$ of them used to take each of vitamin C and iron during pregnancy, 136(69.7\%) of them consumed extra meals during pregnancy while only $5(2.6 \%)$ of them were tobacco smokers/chewers (Table 1). 


\section{Cureus}

Variables $(n=195)$

Mean \pm SD/Frequency (\%)

Birth weight (kg)

Up to 2.5

57 (29.2)

More than 2.5

138 (70.8)

Maternal age (years)

$29.29 \pm 5.22$

Maternal BMI $\left(\mathrm{kg} / \mathrm{m}^{2}\right)$ before pregnancy

Up to 24.9

$53(27.2)$

25.0 or more

$142(72.8)$

Maternal hemoglobin $(\mathrm{mg} / \mathrm{dL})$

$<10$

44 (22.6)

10 to 11

$102(52.3)$

$>11$

$49(25.1)$

Vitamin C intake

Yes

172 (88.2)

No

$23(11.8)$

Iron intake

Yes

172 (88.2)

No

$23(11.8)$

Extra meals consumed

Yes

$136(69.7)$

No

$59(30.3)$

Tobacco smoking/chewing

Yes

$5(2.6)$

No

$190(97.4)$

\section{TABLE 1: Participants profile.}

BMI, body mass index; SD, standard deviation

The study results further showed that most of the neonates $20(45.5 \%)$ with weight less than $2.5 \mathrm{~kg}$ were having the maternal $\mathrm{Hb}$ of less than $10 \mathrm{mg} / \mathrm{dL}$, whereas 39(79.6\%) of neonates were related to the mothers with $\mathrm{Hb}$ of $>11 \mathrm{mg} / \mathrm{dL}$, with a significant association $(\mathrm{p}=0.02)$. It was also revealed that vitamin $\mathrm{C}$ intake $(\mathrm{p}=0.037)$, iron intake $(\mathrm{p}=0.01)$, and consumption of extra meals during pregnancy $(\mathrm{p}=0.021)$ were significantly associated with a LBW of the children, where mothers whose $\mathrm{Hb}<10 \mathrm{mg} / \mathrm{dL}$, no intake of vitamin C, or iron, and extra meals during pregnancy were more likely to have a child with LBW than others (Table 2). 


\section{Cureus}

\begin{tabular}{|c|c|c|c|}
\hline \multirow{3}{*}{ Variables } & \multicolumn{2}{|l|}{ Birth weight (kg) } & \multirow{3}{*}{ p-value ${ }^{*}$} \\
\hline & Up to $2.5 \mathrm{~kg}(\mathrm{n}=57)$ & More than $2.5 \mathrm{~kg}(\mathrm{n}=138)$ & \\
\hline & $n(\%)$ & $n(\%)$ & \\
\hline \multicolumn{4}{|c|}{ BMI $\left(\mathrm{kg} / \mathrm{m}^{2}\right)$ before pregnancy } \\
\hline Up to 24.9 & $20(37.7)$ & $33(63.2)$ & \multirow{2}{*}{0.111} \\
\hline 25.0 or more & $37(26.1)$ & 105 (73.9) & \\
\hline \multicolumn{4}{|c|}{ Hemoglobin (mg/dL) } \\
\hline$<10$ & 20 (45.5) & $24(54.5)$ & \multirow{3}{*}{$0.02^{\star}$} \\
\hline 10 to 11 & $27(26.5)$ & $75(73.5)$ & \\
\hline$>11$ & $10(20.4)$ & $39(79.6)$ & \\
\hline \multicolumn{4}{|c|}{ Vitamin C intake } \\
\hline Yes & $46(26.7)$ & $126(73.3)$ & \multirow{2}{*}{$0.037^{\star}$} \\
\hline No & $11(47.8)$ & $12(52.2)$ & \\
\hline \multicolumn{4}{|l|}{ Iron intake } \\
\hline Yes & 45 (26.2) & $127(73.8)$ & \multirow{2}{*}{$0.01^{*}$} \\
\hline No & 12 (52.2) & $11(47.8)$ & \\
\hline \multicolumn{4}{|c|}{ Extra meals consumed } \\
\hline Yes & $33(24.3)$ & $103(75.7)$ & \multirow{2}{*}{$0.021^{*}$} \\
\hline No & $24(40.7)$ & $35(59.3)$ & \\
\hline \multicolumn{4}{|c|}{ Tobacco smoking/chewing } \\
\hline Yes & $2(40.0)$ & $3(60.0)$ & \multirow{2}{*}{0.631} \\
\hline No & $55(28.9)$ & 135 (71.1) & \\
\hline
\end{tabular}

TABLE 2: Relationship of maternal nutritional and dietary factors with birth weight.

BMI, body mass index

${ }^{*} \mathrm{p}$-value $<0.05$ is considered significant

\section{Discussion}

The current study was carried out to find out the frequency of LBW deliveries and to understand the effect of certain maternal factors on the birth weight of infants. According to regional statistics, the global burden of neonatal mortality was found to be high in low- and middle-income countries (LMICs), where almost all deaths account for LBW cases [5]. There are several associated risk factors for LBW like poor maternal nutrition, anemia, smoking, primiparity, low SES, mental stress during pregnancy, abuse in the family, lack of antenatal visits, short maternal height, and low maternal weight [18]. A study from Botswana revealed that some other factors may also be linked with LBW such as maternal illiteracy, being unmarried, and late or less or no availability of ANC services, and place of birth, while in Egypt, low maternal education was the only factor associated with LBW [19-20]. However, a study from Nigeria depicted that maternal predictors of LBW were marital status, occupation, residential accommodation, and lack of ANC services, hypertension and related diseases, antepartum hemorrhage, and intrauterine growth restriction (IUGR) [21]. In this study, the frequency of LBW was found to be $29.2 \%$. This study finding is comparable with another study also conducted in Karachi, Pakistan, and found that $29 \%$ of women gave birth to LBW babies [10]. We found that mothers whose BMI was less than $25 \mathrm{~kg} / \mathrm{m} 2$ were more likely to deliver LBW babies. In the present study, women with normal BMI gave birth to 73.9\% NBW babies and 26.1\% LBW babies. This finding was consistent with previous studies where the frequency of LBW babies was significantly higher among mothers with BMI $<18.5 \mathrm{~kg} / \mathrm{m} 2$ [22-24]. Another similar study described that lower BMI $(<18 \mathrm{~kg} / \mathrm{m} 2)$ doubles the probability of LBW deliveries [25]. The lower value of BMI indicates that mothers were under-nourished which ultimately restricts the growth and development of a fetus in the uterus. 
It was observed in the present study that females with normal $\mathrm{Hb}$ levels are more likely to deliver NBW, and that there were $79.6 \%$ mothers with normal Hb level gave birth to NBW and 20.4\% LBW babies. Similarly, those women with a very low $\mathrm{Hb}$ level, almost $45.5 \%$ were LBW deliverers, hence, it is confirmed that maternal low $\mathrm{Hb}$ is significantly associated with LBW. Our results are consistent with a previous study where low maternal $\mathrm{Hb}$ was significantly associated with LBW [26].

Imbalance or low dietary intake during pregnancy had adverse effects on birth outcomes [27-28]. It has been observed that in LMICs, women during pregnancy are at high risk of dietary and nutrient deficiencies, including iron, folic acid, iodine, zinc, vitamins A and D, riboflavin, B6 and B12; that is why developing countries especially in Asia, have a high prevalence of LBW deliveries [12, 28-29]. Our findings were also not far from these results; we observed that the women who were taking iron and vitamin C supplements, as well as extra meals during pregnancy, had delivered a lower number of LBW babies and vice versa. It was indicated that the serum concentration of maternal vitamin $\mathrm{C}$ was significantly related to birth weight and length in case of full-term deliveries and that the $1 \mu \mathrm{g} / \mathrm{mL}$ increase in the serum vitamin C level led to a $27.2 \mathrm{~g}$ increase in birth weight and $0.17 \mathrm{~cm}$ increase in birth length. It was also shown that levels of vitamins $\mathrm{C}$ and $\mathrm{E}$ when compared together with birth weight and length, heaviest birth weight and the longest birth length were associated with the highest levels of vitamin C/upper vitamin E [30]. In light of our study, maternal nutritional and dietary factors were found to be very important for fetal development, and they play a significant role in the birth weight of a newborn. Although the study is not spared from bias, this study may have selection bias due to sampling technique used in it,

\section{Conclusions}

The frequency of LBW infants was $29.2 \%$ in this study, which is very alarming because this is the future cause of neonatal death. In this study, we observe that BMI, Hb levels, vitamin C, iron intake, and extra meal intake were the factors associated with LBW deliveries. Hence, the maternal factors mentioned above should be considered important while striving to achieve a good birth weight of infants before and during pregnancy. If we make efforts to prevent or reduce LBW by takings steps and improving maternal nutritional and dietary intake, we will be able to reduce neonatal death. Policy makers may also consider the need for time for quality healthcare, nutrition education, and lifestyle changes in LBW high-risk mothers.

\section{Additional Information \\ Disclosures}

Human subjects: Consent was obtained by all participants in this study. Hamdard University Hospital issued approval 2987165. This study can be conducted as long as humans are kept safe and their information concealed. Animal subjects: All authors have confirmed that this study did not involve animal subjects or tissue. Conflicts of interest: In compliance with the ICMJE uniform disclosure form, all authors declare the following: Payment/services info: All authors have declared that no financial support was received from any organization for the submitted work. Financial relationships: All authors have declared that they have no financial relationships at present or within the previous three years with any organizations that might have an interest in the submitted work. Other relationships: All authors have declared that there are no other relationships or activities that could appear to have influenced the submitted work.

\section{References}

1. Wardlaw TM: Low Birthweight: Country, Regional and Global Estimates . Unicef, 2004.

2. World Health Organization: WHO Global Nutrition Targets 2025: Low Birth Weight Policy Brief . WHO, Geneva; 2014.

3. Lawn JE, Kerber K, Enweronu-Laryea C, et al.: 3.6 million neonatal deaths - what is progressing and what is not?. Semin Perinatol. 2010, 34:371-386. 10.1053/.semperi.2010.09.011

4. Jehan I, Harris H, Salat S, et al.: Neonatal mortality, risk factors and causes: a prospective population-based cohort study in urban Pakistan. Bull World Health Organization. 2009, 87:130-138.

5. Metgud CS, Naik VA, Mallapur MD: Factors affecting the birth weight of a newborn-a community based study in rural Karnataka, India. PloS One. 2012, 7:e40040. 10.1371/journal.pone.0040040

6. He Z, Bishwajit G, Yaya S, et al.: Prevalence of low birth weight and its association with maternal body weight status in selected countries in Africa: a cross-sectional study. BMJ Open. 2018, 8:e20410. 10.1136/bmjopen-2017-020410

7. Elshibly EM, Schmalisch G: The effect of maternal anthropometric characteristics and social factors on gestational age and birth weight in Sudanese newborn infants. BMC Public Health. 2008, 8:244. 10.1186/1471-2458-8-244

8. Khan N, Jamal M: Maternal risk factors associated with low birth weight . JCPSP. 2003, 13:25-28.

9. Saeed A, Saeed AM: Maternal predictors of Low Birth Weight among women attending private hospitals of Lahore, Pakistan. Progr Nutr. 2017, 19:257-263. 10.23751/pn.v19i3.5036

10. Khan FR, Ahmad T, Hussain R, et al.: Relationship among hypovitaminosis D, maternal periodontal disease, and low birth weight. JCPSP. 2018, 28:36.

11. Kramer MS: The epidemiology of adverse pregnancy outcomes: an overview . J Nutr. 2003, 133:1592-1596. 10.1093/in/133.5.1592S

12. Black RE: Micronutrients in pregnancy. Br J Nutr. 2001, 85:193-197. 10.1079/BJN2000314

13. Abubakari A, Jahn A: Maternal dietary patterns and practices and birth weight in northern Ghana . PloS One. 2016, 11:10.1371/journal.pone.0162285

14. Norsa'adah B, Salinah O: The effect of second-hand smoke exposure during pregnancy on the newborn 
weight in Malaysia. Malays J Med Sci. 2014, 21:44-53.

15. Abu-Saad K, Fraser D: Maternal nutrition and birth outcomes. Epidemiol Rev. 2010, 32:5-25.

10.1093/epirev/mxq001

16. Brannon PM, Taylor CL: Iron supplementation during pregnancy and infancy: uncertainties and implications for research and policy. Nutrients. 2017, 9:1327. 10.3390/nu9121327

17. World Health Organization: The Global Prevalence of Anaemia in 2011. Geneva, Switzerland . World Health Organization, Geneva; 2015.

18. Khan A, Nasrullah FD, Jaleel R: Frequency and risk factors of low birth weight in term pregnancy . Pak J Med Sci. 2016, 32:138-142. 10.12669/pjms.321.8120

19. Louis B, Steven B, Margret N, et al.: Prevalence and factors associated with low birth weight among teenage mothers in new Mulago hospital: a cross sectional study. J Health Sci (El Monte). 2016, 4:192-199. 10.17265/2328-7136/2016.04.003

20. Mansour E, Eissa A, Nofal L, et al.: Incidence and factors leading to low birth weight in Egypt . Int Pediatr. 2002, 17:223-230.

21. Olusanya BO, Ofovwe GE: Predictors of preterm births and low birthweight in an inner-city hospital in subSaharan Africa. Matern Child Health J. 2010, 14:978-986.

22. Nagargoje M: A case control study for risk factors of low birth weight in Nagpur city of Maharashtra, India . IJCH. 2007, 22:1-4.

23. Gebremariam A: Factors predisposing to low birth weight in Jimma Hospital south western Ethiopia . East Afr Med J. 2005, 82:554.

24. Siza J: Risk factors associated with low birth weight of neonates among pregnant women attending a referral hospital in northern Tanzania. Tanzan J Health Res. 2008, 10:1-8. 10.4314/thrb.v10i1.14334

25. Wataba K, Mizutani T, Wasada K, et al.: Impact of prepregnant body mass index and maternal weight gain on the risk of pregnancy complications in Japanese women. AOGS. 2006, 85:269-276. 10.1080/00016340500502044

26. Ahmad MO, Kalsoom U, Sughra U, et al.: Effect of maternal anaemia on birth weight. J Ayub Med Coll, Abbottabad. 2011, 23:77-79.

27. Christian P: Micronutrients, birth weight, and survival. Annu Rev Nutr. 2010, 30:83-104. 10.1146/annurev.nutr.012809.104813

28. Haider BA, Yakoob MY, Bhutta ZA: Effect of multiple micronutrient supplementation during pregnancy on maternal and birth outcomes. BMC Public Health. 2011, 11:S19.

29. Torheim LE, Ferguson EL, Penrose K, et al.: Women in resource-poor settings are at risk of inadequate intakes of multiple micronutrients . J Nutr. 2010, 140:2051-2058. 10.3945/jn.110.123463

30. Lee B, Hong Y-C, Lee $\mathrm{K}$, et al.: Influence of maternal serum levels of vitamins $\mathrm{C}$ and $\mathrm{E}$ during the second trimester on birth weight and length. Eur J Clin Nutr. 2004, 58:1365-1371. 